\title{
Inclusões e Inclusões: a Inclusão Simbólica
}

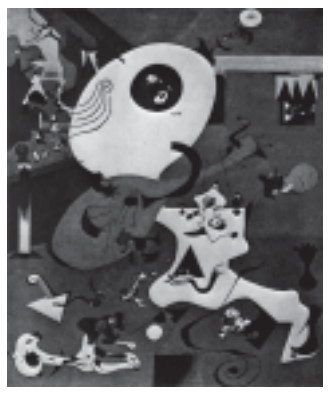

Luiz Fernando Belmonte Mena

Estudante do $5^{\circ}$ ano do curso de Psicologia do Instituto de

Psicologia da

Universidade

de São Paulo (USP).

Muitos são os desafios encontrados na tarefa de proporcionar uma oportunidade de escolarização a crianças com problemas de desenvolvimento. O termo Educação Especial é utilizado hoje de maneira ambígua e contraditória. Uma "inclusão simbólica" configura-se como uma possibilidade real de inclusão, ao contrário das tentativas atuais de "inclusão física" (ou convívio obrigado) realizada em muitas escolas.

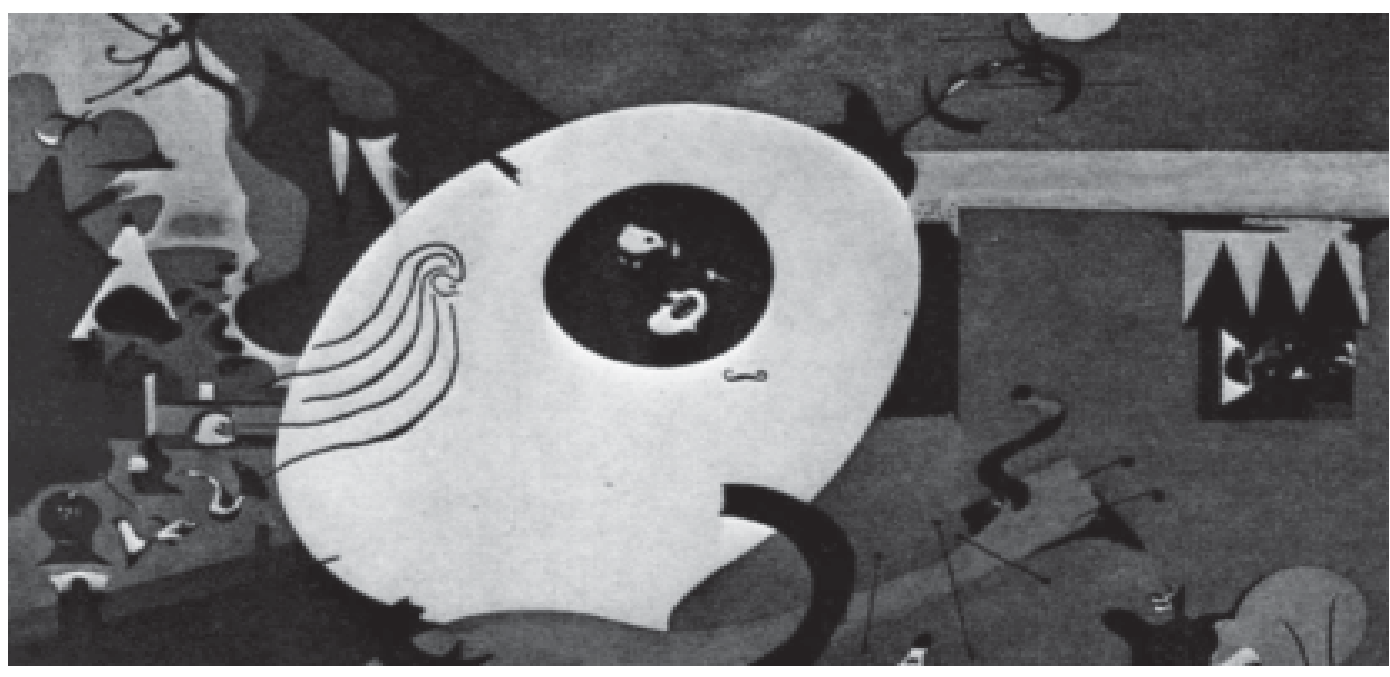

A questão fundamental desta discussão é con-

troversa: a criação de oficinas abrigadas (ou
Ultimamente, muito se tem falado a respeito de inclusão/exclusão social. Desde a exclusão de diferentes grupos étnicos, raciais, religiosos, à exclusão dos pobres e miseráveis; a exclusão das mulheres dos processos produtivos e dos cargos de poder, a exclusão do trabalhador dos processos de trabalho, nas sociedades capitalistas; e a tão falada exclusão das minorias. Traço aqui um recorte, buscando contribuir para a discussão de um tipo específico de exclusão: a das pessoas com deficiência e/ou doença mental, analisando também as alternativas que pretendem a sua inclusão: a "educação especial", e mais especificamente, a importância das Oficinas Abrigadas de Trabalho. Ou seja, a questão da necessidade ou não de uma educação especial, de um trabalho especial, de uma atenção especial. educação especial) permite a inclusão social, possibilitando um acompanhamento diferenciado às pessoas que tenham necessidades especiais, um ritmo diferente para aprender, adequando-se às suas capacidades, conhecimentos e aptidões? Ou pelo contrário, a criação de espaços protegidos só contribui para aumentar a discriminação e o preconceito, excluindo do convívio social as pessoas que são diferentes, limitando-as em um espaço "protegido", longe dos olhos da sociedade?

\section{A Exclusão em Outros Lugares}

O termo "exclusão" é hoje objeto de estudo de diferentes Ciências, e busca dar conta de diferentes fenômenos do mundo. A biologia de Darwin, ao explicar através da seleção natural o processo pelo qual os seres mais evoluídos, mais fortes, mais capazes, mais desenvolvidos, sobrevivem em relação aos mais 
fracos ou menos evoluídos, legitima (em alguns setores) a exclusão social como tendo origem em processos biológicos, naturalizando suas causas. Desse modo, pouco o homem teria como escolha, frente ao determinismo da natureza.

Na Antiguidade, eram comuns atos "seletivos". Mostra-nos Amaral (1995) que, no início da era cristã, Sêneca (4-65 d.C.) justifica o infanticídio argumentando:

“...nós sufocamos os pequenos monstros; nós afogamos até mesmo as crianças quando nascem defeituosas e anormais: não é a cólera e sim a razão que nos convida a separar os elementos sãos dos indivíduos nocivos."(p.46)

Na Grécia Antiga, as pessoas deficientes/diferentes/desviantes tinham, conforme o momento histórico, seu destino selado com a morte, ou simplesmente eram abandonadas. Citando Fustel de Coulanges (1957), Amaral nos conta que o estado greco-romano tinha o direito de não permitir cidadãos disformes ou monstruosos, e ordenava ao pai que matasse o filho que nascesse nessas condições.(1995, p.43)

Platão escreve, em seu Livro III da "República":

“(A Medicina e a Jurisprudência) cuidarão apenas dos cidadãos bem formados de corpo e alma, deixando morrer os que forem corporalmente defeituosos (...) é o melhor tanto para esses desgraçados como para a cidade em que vivem." ${ }^{\prime 1}$

A exclusão social ocorreu desde tempos imemoriais, não só no caso de deformidades físicas ou mentais. Dependendo do momento histórico e da sociedade em questão, ocorreu também através da (des)valorização de atributos, características e comportamentos, como a língua, o credo, a escolha sexual, onde muitas vezes essas características eram dadas como biologicamente determinadas. Como exemplo, cito as idéias de Lombroso $^{2}$, cuja teoria de que os criminosos representam um fenômeno biológico degenerado foi muito difundida no final do século passado, contribuindo para o crescimento do chamado racismo científico. De acordo com ele, os criminosos e depravados teriam um certo tipo de rosto, um determinado formato de nariz, um tamanho de cérebro específico, determinando, assim, as pessoas que teriam tendência à criminalidade e à depravação, tão somente pelas suas características físicas.

Diferentemente da visão naturalista da exclusão, Crochik (1997) aponta para os aspectos culturais e busca neles uma releitura da seleção natural de Darwin. Diz ele que a seleção natural que a biologia propõe, muitas vezes para naturalizar a exclusão, não pode mais ser aplicada da mesma maneira. Atualmente, diz ele, "a cultura ocidental tenta romper a lei da natureza de seleção dos mais aptos, porque há o reconhecimento de que a tarefa de adaptação é coletiva, e porque há o reconhecimento da impossibilidade da auto-sustentação individual desvinculada da cultura". Discute, assim, a importância da convivência com pessoas diferentes/desviantes/deficientes, onde o trabalho de um mostra a incapacidade e a fragilidade do outro, e a possibilidade de somar esforços perante um bem comum diminui a competição, possibilitando o desenvolvimento da civilização.

Ao analisar a formação cultural e suas contradições, Crochik busca os elementos objetivos e subjetivos que permitem a segregação. Mostra-nos ele que a questão da diferença ("Eu sou diferente dele"), como base da segregação, não é necessariamente fruto de preconceito. Ela estaria na essência da humanidade, ou na gênese do processo de humanização. É ela que permite a diferenciação entre as experiências, e a elaboração da subjetividade, na distinção entre dentro e fora, Eu e não-Eu. "A diferença", diz ele, "é o que permite a elaboração do conceito".

Por outro lado, a negação da diferença ("Eu sou igual à ele") não permite a superação do preconceito, mas pelo contrário, o exacerba, na medida em que o mascara. Apesar de o mandamento politicamente correto dizer que somos todos iguais, a dura realidade é que não somos todos iguais. Somos diferentes, e merecemos respeito. Ser diferente - livre de qualquer qualificação, se melhor ou pior, mas ser diferente e só - e assumir a diferença é o primeiro passo para acabarmos com o preconceito. Diz Crochik:
1- in Amaral (1995), p. 44.

2-in Alexander \& Selesnick (1968), p.221. 
“ Isso não quer dizer (...) que o conceito na ciência predisponha ao preconceito, quando ao contrário ele é, ao se relacionar efetivamente com o objeto e não com sua deturpação, um antídoto àquele."(1997, p.13)

\section{Porque Não Diferenciar?}

A negação da diferença pode ser entendida como uma estratégia utilizada para a manutenção do equilíbrio intrapsíquico, através da eliminação da fonte de insegurança, perigo, tensão ou ansiedade. Diz-nos Freud (1919) que a experiência de estranheza só ocorre a alguém quando há algo de semelhante nele, mas deslocado de alguma maneira. O estranho só pode ser experienciado quando ele se diferencia de algo que é familiar. Algumas vezes, esse estranhamento pode causar uma ameaça ao "bem estar" psíquico e social, pela ameaça de mudança que acarreta: mudança do que pensamos, do que acreditamos, do que somos. E mais: mudança das leis que controlam e regem as sociedades, dos padrões culturais, dos paradigmas.

Amaral $(1995)^{3}$ analisa possíveis formas de reação a situações de enfrentamento do diferente ameaçador. Porém, examinemos somente uma delas, de especial importância para a presente discussão. A negação da diferença pode ser expressa na atenuação, na compensação, e na simulação. A atenuação é observada em comportamentos que podem ser traduzidos pelas seguintes frases: "Não é tão grave assim; poderia ser pior". Dessa forma, procura não entrar efetivamente em contato com o outro, e com o sentimento que envolve esse contato: pena, asco etc. A compensação traduz-se em frases do tipo: "É deficiente físico mas é tão inteligente; é autista mas memoriza melhor que uma pessoa normal". A conjunção adversativa mas serve para atenuar a primeira afirmação, compensando-a pela segunda. De outro modo, poderíamos dizer a mesma frase, colocando um e no lugar do mas: Ele é deficiente físico e muito inteligente.

\footnotetext{
3- p.113-117.

4- Comunicação pessoal.
}

A terceira forma, a simulação, é expressa pelas seguintes afirmações: "É cega, mas é como se não fosse; é deficiente mental, mas é como se fosse normal." Não é. Isso não significa atenta para o fato de que devemos observar suas capacidades e deficiências, sem o que não poderemos ajudá-lo de uma maneira real. Vale salientar que as pessoas que são regidas por esses tipos de conduta agem na melhor das intenções. São levadas por sentimentos de assistencialismo, paternalismo, por uma necessidade imensa de ajudar as pessoas. Pensam que acabando com as diferenças, evitarão o preconceito.

Amaral ${ }^{4}$ conta de um dia em que ela chegava à Faculdade de Psicologia na qual é docente. Chovia muito, e ao estacionar o carro na vaga destinada à pessoas com deficiência - ela tem uma deficiência numa das pernas - vaga que está, pelas razões óbvias, posicionada estrategicamente bem em frente à entrada do prédio, percebeu que a vaga havia sido ocupada por uma colega (que não tinha nenhuma deficiência física). Parou então em outra vaga. Mais tarde, ao encontrar essa colega, reclamou de sua atitude, no que esta respondeu: "Porque é que só você pode ter esse privilégio? Você é uma pessoa como todas as outras." Queria dizer com isso: Eu não te diferencio, não te discrimino. Nessa atitude, até bem intencionada, tentava acabar com o preconceito. De maneira inversa, anulando as diferenças entre elas, mostrava sua dificuldade em lidar com o sentimento e a sensação que a deficiência da colega proporcionava nela, e que dessa maneira, a impedia de um real auxílio à amiga.

\section{A Educação Especial}

A questão da educação especial tem sido muito discutida atualmente, mas a questão não é recente. Num primeiro momento, quando de sua concepção e implementação, era aclamada como a salvação para as crianças que não conseguiam - ou não podiam - acompanhar uma classe normal. Nos últimos anos, a opinião dos psicólogos e educadores tem mudado, coincidindo com as publicações e artigos que condenam a educação especial, com o principal argumento de que ela é uma "prática segregacionista". que não tenha nenhum valor, mas somente
O termo Educação Especial define, por um lado, práticas educativas para crianças e adolescentes que precisam de um atendimento, metodologia, atenção e instrumentos específicos que se adequem às suas necessidades 
especiais: deficiência auditiva, física, mental, visual, ou doença mental. Desse modo, é uma conquista da sociedade, na medida em que atende à pessoas que não conseguem usufruir dos processos regulares de ensino, sensibilizando-se e adaptando-se às diferentes necessidades individuais. Por outro lado, o termo Educação Especial é também entendido como uma prática segregacionista, pela maneira como se desenvolveu ao longo dos anos, servindo para legitimar a discriminação e o despreparo das instituições de ensino para lidar com as chamadas "crianças-problema", separando-as das outras crianças. Utiliza-se, para essa separação, de instrumentos "cientificamente validados": as avaliações psicodiagnósticas, feitas pelos psicólogos para encaminhar a criança para uma ou outra classe, ou muitas vezes pedidas pela escola para legitimar a separação já feita pela professora. Segundo Bueno (1993), “a educação especial tem cumprido esse duplo papel na sociedade: de democratização do ensino, e de legitimação da ação seletiva da escola regular."(p.57)

Para discutir a validação, a importância e a eficácia da educação especial, devemos atentar para as várias formas nas quais esta se desenvolveu, e que coexistem atualmente:

1) escolas especiais, especializadas para atender crianças com deficiência física e/ou mental, distúrbios do desenvolvimento, ou com dificuldades de aprendizagem;

2) escolas convencionais, públicas e privadas, que implantaram o sistema de "classe especial", espaço criado para os alunos que apresentam dificuldade em acompanhar uma classe regular.

3) escolas convencionais, que na ânsia de resolver as críticas a respeito da discriminação (feita pelas outras crianças e pelos professores) que uma "classe especial" produz dentro de uma escola, inserem essas crianças em classes regulares, onde convivem com crianças sem deficiência, com o método regular de ensino. São acompanhadas, algumas vezes, por um atendente ou psicólogo (às vezes uma outra professora), dentro da classe, procurando formas de favorecer tanto a integração social quanto o aprendizado.
Há que se fazer uma primeira distinção. Segundo Bissoli Neto (1997), num levantamento junto a professores de educação especial da rede pública, feito em 1995, 20.616 alunos estavam matriculados no ensino especial, dos quais 15.356 (quase 75\%), estavam frequentando classes especiais para alunos com deficiência mental. Consta do levantamento que $90 \%$ desses alunos possuíam avaliação diagnóstica, e 10\% não tinham nenhuma avaliação. Desses 90\%, temos:

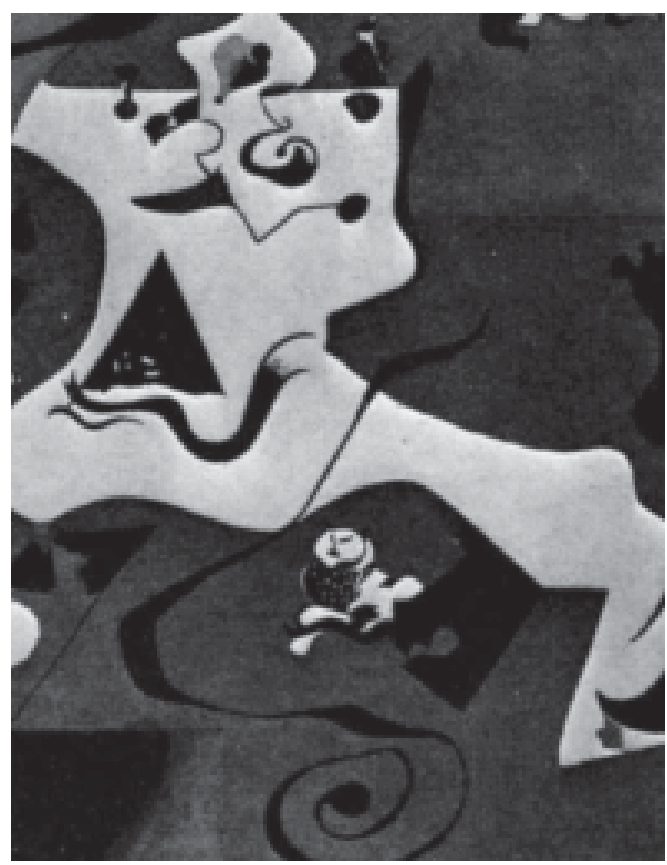

A negação da diferença pode ser entendida como uma estratégia utilizada para a manutenção do equilíbrio intrapsíquico, através da eliminação da fonte de insegurança, perigo, tensão ou ansiedade.

a maioria dos alunos foi encaminhada com o diagnóstico de "educáveis";

outros com problemas de aprendizagem; outros foram diagnosticados como limítrofes;

1 outros foram encaminhados por apresentarem problemas emocionais;

1 outras situações foram encontradas nos encaminhamentos para a classe para deficientes mentais: alunos classificados com autismo; com deficiência auditiva, visual, física; problemas de fala e/ou visão; imaturidade/lentidão; problemas familiares; problemas de agressividade e/ou comportamento; e outros problemas, como gagueira e defasagem de idade.

Observam-se, assim, dados imprecisos de avaliação e diagnóstico, além de erros grosseiros 
que denunciam a falta de critérios rigorosos para tal avaliação. Em um texto sobre as classes especiais, Machado, Souza e Sayão (1997) mostram os "graves equívocos no processo de avaliação psicológica, quer em função de considerar que a base do problema escolar é de caráter estritamente emocional, familiar e cognitivo, quer em função dos instrumentos utilizados tradicionalmente pelos psicólogos para sua realização, limitados no que se refere à avaliação do potencial de aprendizagem escolar."(p.72) Mostram ainda que tais laudos psicológicos consideram a priori que a queixa escolar é fruto de um problema da criança e de suas relações familiares, não levando em conta a escola (que escola é essa, que diretora e professora são essas, que concepções têm acerca dessa criança e de suas atitu-

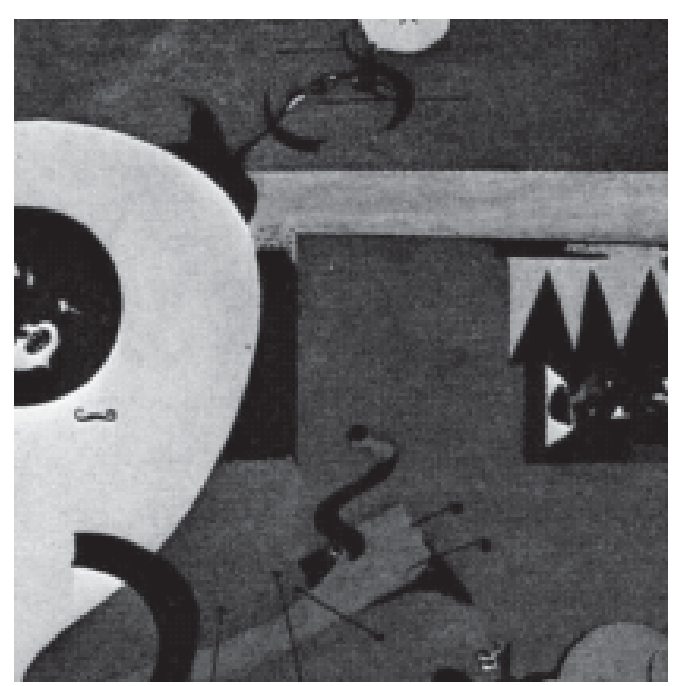

des), e não levando em conta as questões sócio-econômicas que atravessam as relações da criança com a escola - e da escola com a criança - e da criança com o ensino. Dessa maneira, denunciam que, muitas vezes, o problema não está na criança, mas no próprio sistema educacional.

Segundo Bissoli Neto, aproximadamente 55\% dos alunos que freqüentam as classes especiais para deficientes mentais não são clientela da educação especial.

5- Classificação do DSM-IV.

Nesse sentido, devemos diferenciar, para que possamos entender do que falamos e assim, contribuir de algum modo para a discussão: a educação especial existe e está a serviço de duas populações, com duas conseqüên- cias diferentes. Por um lado, ela está servindo para legitimar uma prática discriminatória e segregacionista, atendendo às crianças que "não deveriam estar ali" (crianças que foram, por exemplo, diagnosticadas erroneamente). Por outro lado, existem crianças que realmente têm deficiência mental e/ou doença mental, sérios comprometimentos cognitivos e/ou emocionais, ou os chamados "distúrbios globais do desenvolvimento" ${ }^{\prime 5}$. O ponto, então, que se deve colocar - e que vem sendo esquecido - é que a educação especial pode ser boa e pode ser ruim, depende de para quem e para quê.

Os profissionais que trabalham nas escolas especializadas, nas oficinas abrigadas e nas clínicas psicológicas, sabem que existem crianças que não têm os recursos mínimos necessários de subjetivação, constituição do Eu, ou desenvolvimento cognitivo, que lhes permita acompanhar uma classe normal, ou simplesmente relacionar-se com uma classe normal, e possam beneficiar-se dessa relação. Talvez o nosso desejo fosse realmente o de que a escola e o mercado de trabalho (a sociedade em geral) pudessem realmente acolher a diferença, para que todas as pessoas pudessem viver juntas, integradas. O fato é que uma mudança desse nível exigiria, antes de mais nada, uma mudança na forma como a sociedade está estruturada atualmente, como pensa a diferença, e como lida com ela. Como diz Schwartzman (1997), "nós e nossas crianças teríamos que passar a ver os diferentes, os deficientes e os não capazes como muito mais semelhantes a nós do que nos parece atualmente"(p.65). E não negando as diferenças, sendo simplesmente pessoas.

Mas temos um problema prático: a sociedade não tem, hoje, capacidade de uma integração dessa natureza. O que se vê atualmente é a errônea denominação de "integração" à colocação de crianças seriamente comprometidas em classes normais, onde não há nenhuma condição pedagógica, educacional e terapêutica para que ela aprenda algo, ou para que ela se integre com seus colegas. Muitas vezes, realiza tarefas diferentes das propostas aos demais alunos, orientada ou ajudada por um atendente particular, o que também contribui para aumentar a sensação de estranheza dos outros. 
Colocar junto não significa integrar. Pelo contrário, parece mais uma "integração selvagem", onde a criança está somente no mesmo espaço físico, mas com outra professora, e realizando outras tarefas. Nos mostra Schwartzman (1997) que pretender que indivíduos seriamente comprometidos possam se beneficiar de um programa, método e material formulado para atender a crianças normais é deixar de levar em consideração que a diferença entre ambos é mais do que quantitativa. Desconsiderar essa diferença pode contribuir, por um lado, para aumentar o preconceito e a discriminação, através dos mecanismos que já vimos anteriormente, não permitindo que a diferença seja dita, e não permitindo que os profissionais - psicólogos, professores, educadores - lidem com os sentimentos que tais crianças provocam neles. Misturando-as, tenta-se diminuir a angústia. Por outro lado, não permitimos uma chance verdadeira para que estas crianças possam ter suas capacidades desenvolvidas, através de programas específicos que respeitem suas diferenças. Não permitimos que a criança cresça, do seu jeito, sem que permaneça eternamente na sombra das outras. (A legislação atual tenta, também, sanar o problema, determinando que tantos \% das vagas oferecidas anualmente pelas escolas sejam obrigatoriamente ocupadas por crianças com distúrbios do desenvolvimento. Segundo Schwartzman, apesar de bem intencionada, esta medida visa uma "solução fácil e ilusória para o problema da educação especial".)

Da mesma maneira, a criação das classes especiais também não resolve o problema. Através da separação do espaço físico, através da divisão das classes em normais e especiais, a escola já pré-instala uma separação imaginária, através da classificação: "esta é a classe dos normais, essa é a classe dos outros".

Se a criação das classes especiais tenta resolver, por um lado, o aspecto da facilitação da aprendizagem, através da aplicação de um método e material específico para as crianças, além de um profissional habilitado (condições que nem sempre são respeitadas), ela falha, por outro, ao promover a separação, a rotulação, a discriminação e a segregação. $\mathrm{Na}$ outra alternativa, onde as crianças são colocadas numa classe normal, falham, na maioria das vezes, os dois propósitos: além de não contribuir para a aprendizagem, pois não constitui espaço e método propícios, também não possibilita a integração social, pois não basta estarem juntas para integrarem-se. (Existem alguns trabalhos sendo desenvolvidos nessa direção, com uma "colocação acompanhada" do aluno com deficiência ou doença mental dentro de classes regulares, produzindo resultados positivos, como é o caso do Grupo Ponte, da Pré-Escola Terapêutica Lugar de Vida, na USP. Contudo, vale ressaltar que tal inserção nem sempre recebe tal respaldo técnico, um trabalho de acompanhamento feito junto com a criança, com a família, com os professores, e com a direção da escola. Essa colocação, na maioria das vezes, é descuidada, ou desacompanhada, e somente agrava o problema.)

\section{Educação Terapêutica}

Kupfer (1997) traça um histórico das propostas de educação da criança psicótica, desde os primeiros registros, que datam de 1800, para chegar nas atuais propostas de atendimento. Diz ela que a primeira tentativa de tratamento de uma criança psicótica foi educativa, realizada pelo médico Jean Itard com o pequeno Victor, uma criança encontrada nos bosques da França. Este primeiro tratamento educativo foi uma tentativa de tratar o menino ensinando-o a humanizar-se. Apesar deste início ter sido um fracasso, segundo o próprio Itard, ele inaugurou uma nova maneira de pensar e tratar a psicose: supondo uma humanidade em Victor, ou em outras palavras, supondo um sujeito, que poderia vir a dizer-se.

Essa é a aposta da Educação Terapêutica, que nasceu em Bonneuil com Maud Mannoni e continua em outras instituições, onde tratamento e educação nascem juntos como uma forma de atendimento a crianças com distúrbios do desenvolvimento. Bonneuil está atravessada por um eixo teórico psicanalítico, e segundo a própria Mannoni, de uma forma paradoxal: "O paradoxo de Bonneuil é que não se pratica aí a Psicanálise, mas tudo o que se faz aí baseia-se rigorosamente na psicanálise, à qual não se recorre como técnica de ajustamento mas, outrossim, como subversão de um saber e de uma praxis." 6
... através da divisão das classes em normais e especiais, a escola já pré-instala uma separação imaginária, através da classificação: "esta é a classe dos normais, essa é a classe dos outros".

6 - in Kupfer (1997), p.56 
Essa linha de tratamento é oposta à "apologia do adestramento" hoje praticada na maioria das instituições para autistas, psicóticos e deficientes mentais, onde o importante é ensinálos a atravessar a rua, fechar os botões e ir ao banheiro, sem perturbar os adultos. Mostra Kupfer que a diferença em tratar uma criança como adestrável, diferente de supôr um sujeito onde ainda existe somente uma marca, é que o psicótico "até pode eventualmente aprender algumas palavras, já que elas têm valor instrumental, mas não tem à disposição significantes que o representem, com os quais possa se dizer, e fazer surgir o sujeito."(p.59). Mais uma vez, a questão é ter em mente o que se pretende: de um lado temos a apologia do adestramento, um tratamento que em seu fim último visa a sociedade, seu conforto, bem-estar e o mínimo de incômodo. De outro, uma prática que visa o bem-estar do psicótico, com o objetivo de tirá-lo do gozo mortificador em que está mergulhado, ajudálo a nomear esse gozo, e assim, posicionar-se na cadeia simbólica. Uma Educação Terapêutica, que mais que as palavras, preocupa-se com a articulação entre palavra e significante, entre palavra e emergência do sujeito.

\section{O Trabalho}

As Oficinas Abrigadas de Trabalho inseremse, ao meu ver, também sob o termo Educação Especial. Elas foram criadas como uma alternativa para essas crianças com deficiência e/ou doença mental que, ao crescerem e tornarem-se adultos, saem da escola (os que frequentaram uma escola) e não conseguem uma inserção no mercado de trabalho. Muitos deles ficam em casa, ajudando a família em pequenas tarefas domésticas. Têm seu desenvolvimento retardado (ou até impedido) em suas diversas formas possíveis (cognitivo, motor, emocional, artístico, intelectual etc.), para o qual é indispensável o contato com a sociedade e a cultura, com seus elementos constitutivos, com o Outro, responsável pela construção do corpo e do sujeito psíquico, dos limites e das bordas. Dentre esses elementos, dois são de especial importância: a escola, que ajuda na construção de uma identidade de criança, e o trabalho, alicerce da identidade adulta (pelo menos na nossa cultura). assim, de uma necessidade do adulto com de-

ficiência e/ou doença mental, como uma possibilidade de desenvolvimento bio-psico-social, através de sua inserção no mundo do trabalho. Realizam aí diferentes atividade artesanais, na maioria das vezes sem fins lucrativos, além de outras atividades pedagógico-terapêuticas, como música, educação física etc.

Através de um estudo realizado sob a supervisão de Fábio de Oliveira, do CPAT-USP (Centro de Psicologia Aplicada ao Trabalho), foi feita uma análise institucional de uma Oficina Abrigada, a Alternativa, procurando entender qual era o papel e a importância do significante trabalho para as pessoas com deficiência e/ou doença mental. Este estudo tomou outras proporções, na medida em que foram aparecendo questões que permeavam o funcionamento da instituição, de seus objetivos implícitos aos imaginários, no tratamento dos distúrbios do desenvolvimento. Assim, passamos a procurar o sentido do trabalho para a instituição, e como esse significante institucional contorna o significado do trabalho para as pessoas que lá trabalham.

Procuramos no estatuto da entidade as diretrizes que regem o funcionamento da Oficina. A principal dúvida era saber se a Oficina tinha como meta a profissionalização dos artesãos, e se assim fosse ela serviria como um meio para possibilitar uma futura inserção no mercado formal de trabalho. Por outro lado, se seu objetivo era tão somente (como se fosse pouco) possibilitar o desenvolvimento biopsico-social do artesão, onde o trabalho seria um instrumento (valiosíssimo) a mais, mas não visando diretamente a inserção no mercado formal.

No primeiro caso - profissionalizante - a Oficina seria um meio para alcançar um fim outro. No segundo - terapêutica - a Oficina seria um fim em si mesma, no sentido de que não visaria tanto o "resultado" (o aprendizado de técnicas de trabalho), mas o próprio processo através do qual ele pode se desenvolver. Seguindo estes dois possíveis caminhos, teríamos: na primeira hipótese, a Alternativa, como oficina profissionalizante, tendo como objetivo a reinserção da pessoa na sociedade, visando capacitá-la, através do aprendizado de técnicas, servindo como um meio para que possa ingressar em um trabalho real. 
Assim:

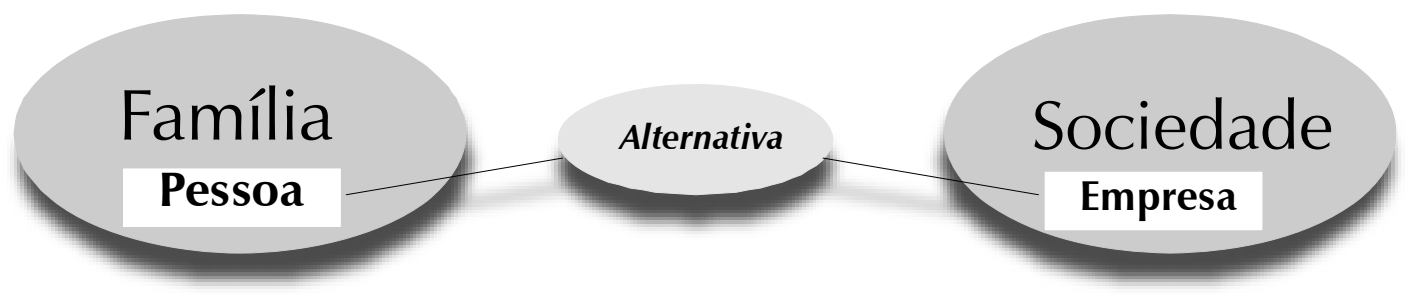

Na segunda hipótese, a Alternativa, como Oficina Abrigada de Trabalho, visaria o desenvolvimento do sujeito, buscando sua integração e participação no grupo social em que vive - seja a família, a própria Oficina (e seus integrantes), ou a sociedade de maneira geral. Assim, busca defender o direito para que eles tenham acesso aos recursos sociais existentes, como a música, a educação física, o batuque, a escolaridade, e o próprio trabalho. Este não visaria o lucro ou a produtividade em si, mas seria um elemento para a realização pessoal (e profissional) da pessoa com deficiência. Nesse sentido, a Oficina não seria um meio.

Assim, temos:

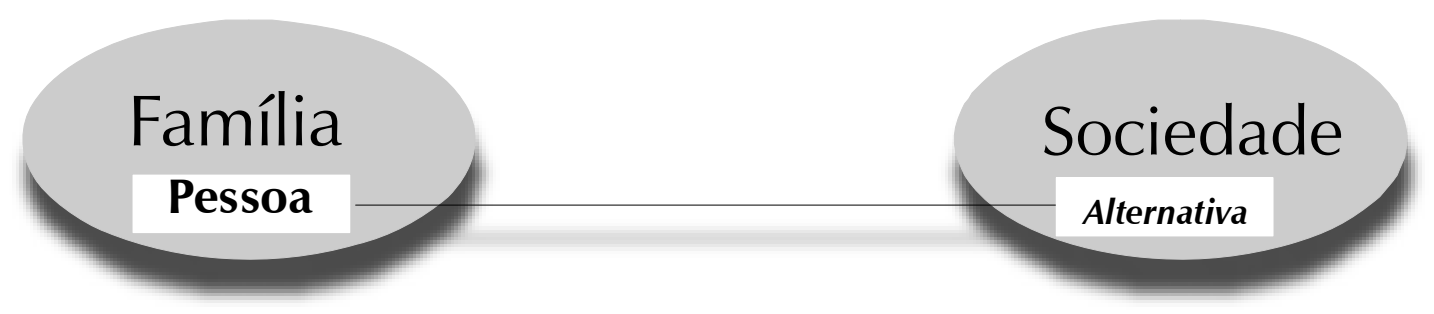

Desta maneira, a Alternativa, como instituição da sociedade, como representante legítima e concreta da cultura, assegura já a integração, no que eu chamo de "Inclusão Simbólica". Para explicar tal posição, temos que lembrar que, ao falarmos em inclusão na sociedade, devemos pensar que a "socieda-

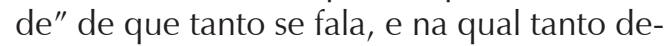
fende-se a inclusão, é um corpo teórico e abstrato. Ela só existe concretamente através da cultura e de seus elementos constitutivos. (O "Outro" só existe e se materializa nos "outros") É nas instituições que ela toma forma, na família, escola, trabalho, igreja etc, e através delas, nos elementos da cultura dos quais todos nós compartilhamos: a língua, a escrita, a leitura, as danças (o "balé das meninas"), os esportes (o "futebol dos meninos"), a pintura, as artes plásticas, a música, o cinema, o batuque do carnaval e da capoeira, e até o cartão de ponto que se bate na entrada e na saída do trabalho, ou o salário que se ganha no fim do mês etc etc etc.)
Estes elementos constitutivos da cultura estão espalhados pelas ruas, pelas bancas de jornais, pelas lojas, na televisão, na farmácia, no ônibus. Estão "disponíveis a todos" e possibilitam a construção da subjetividade. Através deles, nós somos quem somos, e através deles nos sentimos representantes da sociedade, e podemos reconhecer o outro também como representante.

Eu poderia ilustrar esse reconhecimento no meu trabalho com música, no chamado "Grupo do Batuque", uma das atividades oferecidas na instituição. Será que eu deveria tentar colocar um aluno meu numa bateria de escola de samba, como a Mangueira? Será que assim eu estaria promovendo sua integração na sociedade? Provavelmente não. Mas fazendo uma bandinha na Alternativa eu estou, porque batucar o samba que todos batucam é integrar. Usar a timba, o reco-reco, o agogô, o tamborim, o pandeiro, que todos usam, é integração. E quando um sambista ouve e se 
identifica com as pessoas, com os instrumentos, com o grupo, e reconhece-os como sambistas, assim como ele, isso é integração. A isso eu chamo "Inclusão Simbólica": a autorização e a permissão para que os elementos culturais sejam compartilhados por todos, e através desse compartilhamento, possam ser reconhecidos como pertencentes, integrantes e representantes da cultura.

Por muitas razões, as pessoas com deficiência ou doença mental "não podem servir-se" (ou não têm permissão para) dos elementos da cultura: não freqüentam uma escola, não trabalham, não tocam um instrumento, não pegam um ônibus. Muitas vezes ficam somente em casa.

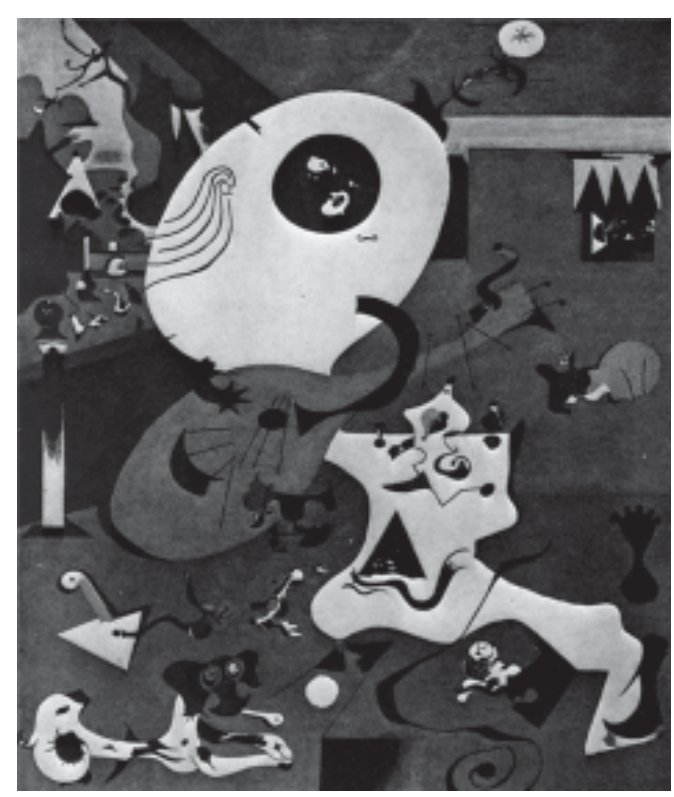

\section{Oferta de Significantes}

O pano de fundo para a análise feita com a Alternativa - se servia como um meio ou se era um fim em si mesma - retoma a questão da Educação Especial, que sempre deve estar presente, ao analisarmos os objetivos das instituições: para quê educar. Mais uma vez, corremos o risco de almejar a apreensão de aptidões e conteúdos (ou palavras), para fazer o psicótico ocupar um lugar em algum lugar, revelando assim que de fato ele não ocupa (e nunca ocupou) lugar algum. Nesse caso, no dizer de Lerner (1997), "a criança ocupa, ainda, o lugar da falência do ideal".(p.69)
A "inclusão simbólica" configura-se, então, como uma forma possível de inclusão, no acesso aos elementos da cultura, através dos quais nos reconhecemos e reconhecemos o outro. Integração é reconhecimento. É assim que uma escola especial (ou oficina abrigada) pode possibilitar a inclusão e a integração, através de todas as atividades que propõe, através dos elementos que capta e oferece, pondo à disposição de pessoas que, de outro modo, estariam impossibilitadas de procurarem por si mesmas esses elementos, impossibilitadas de estudar, de trabalhar, de tocar um instrumento, de pertencer. Da mesma maneira, eu acredito que a colocação dessas pessoas numa fábrica qualquer, onde provavelmente realizariam uma atividade repetitiva e estereotipada, seria uma falsa inclusão, onde provavelmente - como a experiência nos mostra - seriam discriminadas e deixadas de lado, numa pseudo-inclusão, assim como colocar um autista numa classe normal.

Assim, concluindo nas palavras do psicanalista Alfredo Jerusalinsky (1997), a proposta de uma Educação Especial esbarra, inevitavelmente, com os "perigos da discriminação e da marginalização, e também com uma dura resistência familiar e social. Uma dura resistência freqüentemente formulada num falso democratismo, que confunde uma questão de sintoma com uma questão de direito, num igualitarismo puramente imaginário, muito mais destinado a satisfazer o narcisismo dos profissionais do que as verdadeiras necessidades das crianças que padecem destas dificuldades."(p.93)

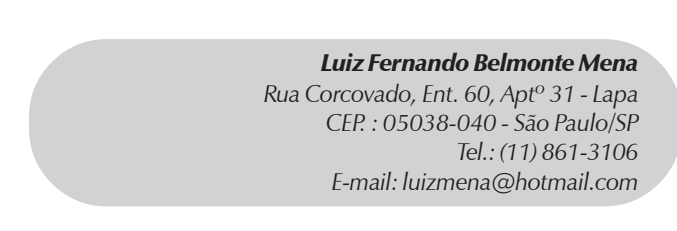


Alexander, F.G. \& Selesnick, S.T. (1968). História da Psiquiatria. São Paulo: Ibrasa.

Amaral, L. A. (1995). Conhecendo a Deficiência (em Companhia de Hércules). São Paulo: Robe.

Bissoli N. J. (1997). Legislação e Situação Atual das Classes Especiai no Estado de São Paulo. Em Educação Especial em Debate (pp.55 65). Conselho Regional de Psicologia, São Paulo: Casa do Psicólogo.

Bueno, J. G. S. (1997). A Integração Social das Crianças Deficientes: a Função da Educação Especial. Em M. T. E. Montoan, (Org.), A integração de Pessoas com Deficiência: contribuições para uma reflexão sobre o tema (pp.57-61). São Paulo: Memnon, Editora Senac.

Crochik, J. L. (1997). Aspectos que permitem a segregação na Escola Pública. Em Educação Especial em Debate (pp.13-22). Conselho Regional de Psicologia, São Paulo: Casa do Psicólogo.

Freud, S. (1919). El Siniestro. Em Obras Completas de Sigmund Freud,

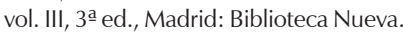

Jerusalinsky, A. (1997). A escolarização de crianças psicóticas. Em Estilos da Clínica - Revista sobre a Infância com Problemas (pp.72-95). São Paulo: Pré-Escola Terapêutica Lugar de Vida - IPUSP, V.2, № 2 .
Kupfer, M. C. M. (1997). Educação Terapêutica: O que a Psicanálise pode pedir à Educação. Em Estilos da Clínica - Revista sobre a Infância com Problemas (pp. 53-61). São Paulo: Pré-Escola Terapêutica Lugar de Vida - IPUSP, V.2, no 2 .

Lerner, R. (1997). Escolarização de crianças com Distúrbios Globais do Desenvolvimento: dados e reflexões a respeito dos aspectos envolvidos. Em Estilos da Clínica - Revista sobre a Infância com Problemas (pp.62-71). São Paulo: Pré-Escola Terapêutica Lugar de Vida - IPUSP, V.2, no 2 .

Machado, A.; Souza, M. \& Sayão, Y. (1997). As Classes Especiais e uma Proposta de Avaliação Psicológica. Em Educação Especial em Debate (pp.69-116). Conselho Regional de Psicologia, São Paulo: Casa do Psicólogo.

Schwartzman, J. S. (1997). Integração: Do Que e De Quem Estamos Falando? Em M. T. E. Montoan, (Org.), A integração de Pessoas com Deficiência: contribuições para uma reflexão sobre o tema (pp.6269). São Paulo: Memnon, Editora Senac.

Silva, O. M. (1993). Uma Questão de Competência. São Paulo: Memnon.
Referências bibliográficas 